\title{
Imaginarios posapocalípticos en el cine actual: entre la vuelta al origen y el fin de la humanidad
}

\author{
Gérard Imbert \\ (Universidad Carlos III de Madrid)
}

Recibido: $2 / 4 / 2014$

Aprobado: 23/4/2014

\begin{abstract}
Resumen: En el cine actual, los imaginarios proyectados en el futuro reflejan las inquietudes de hoy. Surgen películas que se sitúan en un después del apocalipsis o que lo anticipan, que expresan un «imaginario del fin», como he llamado a estos fantasmas de muerte que pesan sobre la posmodernidad. Hoy, la amenaza, el peligro de desaparición, ya no viene de fuera (invasiones, extraterrestres, bestias de otros mundos, catástrofes naturales), sino de dentro, de la propia sociedad. A partir de películas recientemente estrenadas, se analizará la emergencia de estos imaginarios: desde la vuelta regresiva al origen hasta el fantasma del fin de la humanidad.
\end{abstract}

Palabras clave: cine / imaginarios / apocalíptico / desaparición / muerte

\section{Post-apocalyptic imaginaries in contemporary cinema: between returning to the origin and the end of humanity}

Summary: In the contemporary cinema, the imaginaries projected on future reflect the present preoccupations. Appear pictures that are situated after apocalypse o anticipate this, that express a «imaginary of end», as I called those fantasmatic representations about death that threaten the modernity. Today the menace, the extinction risk don't derive from outside (invasions, aliens, monsters from another worlds, natural desasters) but from inside, from the own society. Based on recent pictures, this study analyzes the apparition of those imaginaries: from the regressive return to the origins to the fantasmatic representation of the end of humanity.

Key words: cinema / imaginaries / apocalyptic / extinction / death 


\section{Introducción: imaginarios del fin}

$\mathrm{E}$ n el cine actual, más que nunca, los imaginarios proyectados en el futuro reflejan las inquietudes de hoy, la inestabilidad del presente, la incertidumbre vinculada a la ausencia de futuro, las turbulencias políticas y las amenazas económicas. Enraizadas en este malestar civilizacional, surgen películas que se sitúan en un después del apocalipsis o que lo anticipan (Take Shelter, 2011, de Jeff Nichols; Noé, 2014, de Darren Aronofsky), que dan por sentados el fracaso y, a veces, la destrucción del reino humano, que expresan un miedo a la disolución de todo, a la pérdida de los límites. «Imaginario del fin» he llamado a estos fantasmas de muerte que pesan sobre la posmodernidad (Imbert, 2010a).

Pero, hoy, la amenaza, el peligro de desaparición, ya no viene de fuera (invasiones, extraterrestres, bestias de otros mundos, catástrofes naturales), sino de dentro, de la propia sociedad. Atrás han quedado las grandes películas apocalípticas de Roland Emmerich, con su invasión de alienígenas (Independence Day, 1996) y sus alteraciones climáticas (El día de mañana, 2004, y 2012, 2009). Ahora, el mal no es tan visible, se ha incorporado a nuestro mundo $y$, a menudo, se extiende de manera viral, en forma de contagio. El otro se ha apoderado del sujeto, el enemigo es interior, como ocurre con el terrorismo en el ámbito político... Obviamente, la destrucción de las Torres Gemelas tiene sus secuelas en el imaginario colectivo, alimentando el miedo y a que el caos domine sobre el orden; pero hay algo más, la idea que aparece en filigrana en muchas películas de que ya no vivimos, sino que sobrevivimos, que trae consigo el fantasma de la deshumanización del ser humano.

Películas tan diferentes como Contagio (2011) de Steven Soderbergh, El caballo de Turín (2011) del húngaro Béla Tarr, Melancolía (2011) del danés Lars von Trier, After Earth (2013) de M. Night Shyamalan o Guerra mundial Z (2013) de Marc Forster dan fe de ello.

Todas - así como las que veremos más adelante- expresan un miedo intangible, difuso, propio de la posmodernidad: el miedo a la catástrofe, el miedo a que esto acabe. Sin duda, este miedo se deriva del estado del mundo, pero también de la capacidad de los medios de amplificar las amenazas y cultivar nuevas figuras del mal. «Miedo líquido», lo ha llamado Zygmunt Bauman (2007), el cual consiste en «volver a escenificar el Apocalypse Now», ya no el de la película de Coppola, sino el de todos los días:

Los miedos que emanan del síndrome Titanic son miedos a un colapso o a una catástrofe que se abata sobre todos nosotros y nos golpee ciega e indiscriminadamente, al azar y sin ton ni son, y que encuentre a todo el mundo desprevenido y sin defensas (Bauman, 2007, p. 31).

Tras todo ello, hay un macromiedo, el miedo pánico a la muerte, que vuelve 
como el gran reprimido de la modernidad y que el cine hipervisibiliza hoy en día (Imbert, 2010b). Bauman describe así ese miedo: «El miedo primario a la muerte es, quizás, el prototipo o el arquetipo de todos los miedos, el temor último del que todos los demás toman prestado sus significados respectivos».

\section{Imaginarios posmodernos}

Frente a esta angustia cósmica, que encubre una profunda angustia existencial, se vislumbran dos orientaciones. La primera es la vuelta al origen - al objeto perdido- en un viaje regresivo a los orígenes del género humano. Origen (2010) de Christopher Nolan y Prometheus (2012) de Ridley Scott son su ilustración más llamativa; y, con ello, la vuelta a unas formas primitivas de vida, como en Avatar (2009) de James Cameron. En la segunda orientación, se encuentran las visiones posapocalípticas que parten del supuesto de la desaparición de lo humano e incluso del planeta Tierra, para dejar lugar a la catástrofe o plantear un volver a empezar desde cero.

Estos imaginarios pueden generar otras expresiones que tienen consecuencias en la representación del mundo (histórico y social) y en la relación con el entorno natural. Cobran formas muy diversas:

- La prevalencia de espacios fantasmáticos sobre los reales -lo que he llamado lo espectral (en Tropical
Malady, 2004, del tailandés Apichatpong Weerasethakul; en Anticristo, 2009, de Lars von Trier) - o de otras dimensiones - no racionales, metafísicas- sobre las naturales, como ocurre en la obra del propio Shyamalan.

- Facilitan lo que podríamos llamar una estética de la desaparición: el cultivar estéticamente la idea del fin de todo, dentro de una aceptación resignada o melancólica. El caballo de Turín de Béla Tarr y Melancolía de Lars von Trier lo traducen al pie de la letra.

- Fomentan conexiones secretas entre los hombres, entre las cosas y son propensos a viajes en el espacio, el tiempo, pero también en las identidades y las categorías, con sus derivas directamente new age: desde Caótica Ana (2007) de Medem, hasta Looper (2012) de Rian Johnson, El atlas de las nubes (2012) de los hermanos Wachowski y Tom Tykwer o Bestia del sur salvaje (2012) de Benh Zeitlin.

¿Son estas nuevas formas de evasión de la realidad? ¿En qué medida no son profundamente ambivalentes porque oscilan entre la ficción y la creencia, lo fantástico (la ciencia-ficción) y lo imaginario (las angustias propias de nuestro tiempo)? Esta confusión de mundos y de niveles se ve acentuada por la tendencia a producir relatos en los que se emborronan los límites entre categorías (lo real y lo imaginario) mediante hibridación de géneros, y 
también, los límites entre géneros (la ficción y el reportaje).

Juegan con lo que he llamado lo intersticial, la disolución de las fronteras entre categorías o las intersecciones entre ellas: cuando no sabemos si estamos en una o en otra, como ocurre en la serie sueca Real Humans (2012), creada por el sueco Lars Lundström, donde los androides (llamados hubots en la película) se humanizan hasta poder sentir y los humanos se encariñan con ellos como si fueran de la misma especie. Juegan también con la hibridación de géneros como en Catfish (2010), la película de Ariel Schulman y Henry Joost, donde el reportaje se confunde con la ficción, hasta descolocar al espectador, hacerle dudar en cuanto al «estatus de veridicción» del relato, la naturaleza de lo que estamos viendo. Lo pueden hacer hasta el vértigo, jugando con los roles narrativos, por ejemplo, perturbando la diferenciación entre manipulador y manipulado, como hacen Christopher Nolan o Rian Johnson.

Con esto rompen con la lógica moderna - el principio de no contradicción, entre otros- y cultivan lo ambivalente (Bauman, 2005): el que algo pueda ser una cosa y, al mismo tiempo, su contrario, sin que haya contradicción lógica, como en Looper, con sus reencarnaciones, su anticipación del presente y su incidencia en él (el sueño de poder cambiar el curso del tiempo). $\mathrm{O}$ pervierten el contrato que vincula al lector con el texto fílmico, alteran- do el orden de la representación como en Origen, con su juego de cajas chinas (los sueños dentro del sueño).

La mayoría de estas películas recurre a la ciencia-ficción, pero no tanto como género cerrado, sino como vehículo para plasmar las angustias de nuestra época en torno al tiempo y a la historia, amén de las dudas identitarias del sujeto contemporáneo.

De hecho, la ciencia-ficción ya no es un género en sí - un género de evasión vinculado con lo fantástico-, sino que se ha transformado en un medio expresivo para traducir las dudas en cuanto a la relación con el mundo natural y social, un pretexto para plasmar con total libertad $-\mathrm{y}$, de paso, exacerbar- los imaginarios actuales. Y lo hace cambiando la relación entre las fuerzas destructivas y el hombre, cultivando un nuevo imaginario: la autodestrucción de la Tierra por el hombre. De ahí que la angustia, el pánico ante lo desconocido ya no vengan tanto de otros universos, de mundos ajenos, como del propio mundo, de la posibilidad de perturbar sus categorías (como ocurre en Origen), hasta meterse en el inconsciente del hombre y reprogramar la historia (mediante la precognición, o sea, el poder de influir en el curso de los acontecimientos). $\mathrm{O}$, caso más grave, la angustia procede de la propia pulsión destructiva del hombre.

Surge así otro imaginario, que consiste en jugar con el tiempo y el espacio, en anular o manipular la realidad 
objetiva (la material y la humana). Si puedo viajar en el tiempo, puedo incidir en los eventos y borrar anticipadamente acciones que se pudieran hacer reales (como en Looper). A los tradicionales viajes en el tiempo, desde Julio Verne hasta los hermanos Wachowski (en Matrix (1999) y El atlas de las nubes (2012), suceden los viajes anticipatorios. La precesión (Baudrillard, 1978) suplanta a la retrocesión, el viaje en el imaginario y en lo virtual sustituye al viaje en el espacio; la manipulación y la especulación desalojan a lo aventurero y conjetural. Si me puedo volver invisible, escapo a la realidad objetiva y supero mis emociones, como pasa en After Earth de Shyamalan.

Estamos más allá de la ciencia-ficción en la medida en que la duda sobre la existencia del universo ha alcanzado y contaminado nuestro propio universo, nuestra percepción y, además, su representación: ¿es real todo lo que parece como tal? ¿Dónde están los límites entre lo real y lo imaginario? ¿No vivimos una época de fantasmación, no en el sentido mágico en que lo entiende Shyamalan, sino en el sentido psicoanalítico de fantasear, vivir de «proyecciones fantasmáticas» - como las llamo-, que son el reflejo del deseo y no de la imaginación, son del orden de la necesidad asumida y no proceden solo del exclusivo consumo mediático. En El sexto sentido (1999), el niño se mete literalmente en la mente del adulto; en La joven del agua (2006), el ser mitológico irrumpe en el mundo de los huma- nos e interviene en sus disposiciones mentales y predisposiciones espirituales, hace de revelador de las identidades profundas u ocultas.

Lo fantasmático está hoy, a través de los imaginarios, totalmente integrado a lo real. Estamos más allá de la imaginación (la invención que alimentaba al género fantástico). Nos vemos proyectados en mundos virtuales, más allá de los «mundos posibles» de la ficción y más acá de la representación, en un acercamiento a lo real (lo irreductible, lo inefable, lo irrepresentable) que enraíza en el inconsciente, se nutre de los imaginarios. De ahí una demanda de crudeza - aunque solo sea a través de imágenes y representaciones-, la reivindicación de una intimidad a ultranza, una frontalidad con el horror, un hardcore representacional y consumista que hace que las barreras de lo secreto hayan saltado, que los límites del pudor ya no sean los mismos. Si no es visualizado - expuesto-, nada vale de por sí. El acceso a lo real pasa por su proyección virtual y su exposición mediática. Ni real ni ficticio, ese es el reino de la proyección, de la creación de espacios proyectivos, profundamente ambivalentes.

\section{De la angustia existencial a la vuelta al origen}

Si After Earth (2013) representa la vuelta al origen perdido, Origen (2010) de Christopher Nolan y Prometheus (2012) 
de Ridley Scott reflejan una indagación en el origen que perturba totalmente las categorías sensoriales en la primera y las conceptuales en la segunda.

En Origen, Dom Cobb, un ladrón de alto vuelo, de mucho prestigio en el mundo del espionaje corporativo, pero que es ahora un fugitivo, se ha especializado en robos sutiles. Mediante un dispositivo maquiavélico consigue penetrar en las profundidades del subconsciente de los demás durante el sueño y orientar sus decisiones (inception, de acuerdo con el título original, es esa implantación de una idea en la cabeza de otro). Ahora se le presenta la oportunidad de redimirse. En lugar de robar, se va a introducir en la mente del heredero de una multinacional para incidir en sus decisiones. El sueño -tal vez lo más real de la mente humana: lo más bruto, informe, lo menos formalizado en lenguaje racionaldeviene entonces en una especie de terreno de juego en el que Dom Cobb va a intervenir para desviar los pensamientos del otro como si fueran el producto de unas jugadas de la mente. De hecho, el director muestra el universo de los sueños como una especie de juego de video on-line.

Es interesante -aunque en parte fallido- el intento del director de recrear el universo de los sueños como un mundo con sus propias leyes, donde ya no impera la lógica racional, sino otra onírica, que perturba totalmente las categorías espacio-temporales, subvierte los planos. Pero, retomando la estructura narrativa del perseguidor perseguido, el director nos muestra cómo el manipulador de sueños va a ser él mismo perseguido por un sueño que afecta a su propia historia y que funciona como una especie de «escena primitiva» que lo ha marcado y determina toda su vida, un episodio oscuro de su vida anterior relacionado con la muerte de su esposa.

Aquí el origen es claramente fantasmático, dentro de un juego de cajas chinas en el que los sueños ajenos despiertan a su vez un sueño suyo: ve a la esposa muerta como un espectro y revive la escena de su muerte. Como el protagonista de Shutter Island (2010) de Martin Scorsese, Cobb es víctima de un sentimiento de culpabilidad, a lo que se añade el sentimiento de duda que afecta a la realidad misma de lo que ve/(re) vive. Alucinación, sueños despiertos y fantasmación se confunden aquí. En su intento de «robar» el sueño de los demás y, con él, su inconsciente para poder actuar sobre sus decisiones futuras, se ve él mismo atrapado por esta visión fantasmática y lastrado por ella.

En su «teletransportación» al mundo de los sueños, el entorno sufre alteraciones que, como en la toma de algunas drogas alucinógenas, se traducen en distorsiones espacio-temporales. Conocíamos los viajes en el tiempo, lo novedoso aquí son los viajes en el espacio, con la alteración de los planos y de las dimensiones. Como en la teoría de los pliegues, el espacio no es una superficie plana, sino que se 
pueden romper, ondular o invertir los planos, tanto los horizontales como los verticales. Son, sin duda, los momentos más espectaculares de la película: cuando el espacio escapa a sus leyes, las superficies se suben literalmente a las paredes y el hombre pierde todo control sobre el espacio.

Una vez más, estamos ante un imaginario de la distorsión, que puede corresponder a un pánico a la desintegración, a la pérdida de las coordenadas, un imaginario del caos, pero ya no encarnado en el desorden, la destrucción material, la violencia ajena o las invasiones procedentes de otros planetas -como aparece en muchas películas de catástrofes-, sino que procede de un miedo a que se desregulen las leyes físicas más elementales, en particular, todo cuanto regula nuestra relación fundamental con el entorno: lo espacial y lo temporal.

Vuelta a lo informe, a un estadio de caos originario, a un estado preconsciente - como es el sueño, dominado por el inconsciente-, el fantasma aquí es regresivo, no proyectado hacia el futuro, como en la ciencia-ficción clásica, hacia la degradación de lo existente por una fuerza humana o suprahumana, sino que enraíza en los abismos del inconsciente, como si volviéramos a un estadio prerracional, en el que el hombre ni siquiera se controla a sí mismo.

Hoy, el miedo ya no procede tanto del otro como del propio sujeto, se traduce más en el enfrentamiento con uno mismo que con el otro. Ese miedo es intrínseco al hombre y a su relación con su propio entorno. ¿Será porque ya no estamos a gusto en esta Tierra? La cuestión es fundamental: es lo que funda nuestro asentamiento en la realidad, es anterior incluso a la relación social. El cine actual nos habla directamente de ello.

Prometheus (2012) de Ridley Scott lo hace a su manera, confusa, grandilocuente, alucinatoria, como una vuelta a la esencia de todo, un descenso en el pozo sin fondo de la historia del hombre. Por muy diáfana que intente ser la evocación de este viaje, no deja de tener algo oscuro, como todo intento de acercarse al origen. La dramaturgia espectacular de Nolan, su pretensión a ser un relato a lo Philip K. Dik, al modo del thriller, o de igualarse a una pesadilla como las de Lynch en Mulholland Drive (2001), deja paso en Scott a un relato enrevesado, efectista, plagado de incongruencias narrativas y de teorías estrafalarias, con un fondo new age, remanentes cristianos y el reciclaje de otras películas de ciencia-ficción.

El argumento es simple: un multimillonario en el umbral de la muerte quiere indagar sobre el tema para encontrarse con sus creadores, no por filantropía, sino porque espera que esto pueda permitirle acceder a la vida eterna. Para dicho cometido manda a una aparatosa expedición espacial en una nave nombrada Prometheus. 
Por mucho que lo niegue el director, el que sea una precuela (una vuelta sobre los orígenes de un relato anterior) de Alien, el octavo pasajero (1979), del propio Scott, no hace sino abundar en esta indagación en el origen, aunque sea narrativo en un principio. No es casual aquí que haya que ir a buscar el secreto sobre el origen del hombre en otras civilizaciones. El hombre ha perdido su propia historia, cuya genealogía está en poder de otro, una avanzada civilización de alienígenas. Se ha cortado de su origen. Vive en la ilusión.

Disfrazada de ciencia-ficción, con un barniz de referencias seudocientíficas, la película nos proyecta en 2089, pero tiene mucho de relato mitológico. Aunque ingenuo - y más allá del mito de Prometeo-, no deja de reflejar el malestar ante el origen y la búsqueda de un relato fundacional, de algo que lo explique todo sin recurrir a la religión, pero sin tampoco acudir a las teorías existentes sobre la creación del mundo. El misterio consiste en entender por qué los «ingenieros» alienígenas crearon a la humanidad y luego la destruyeron. Aquí también es como si la humanidad no se bastara a sí misma y el hombre se viera desposeído de su propia historia y, como en el cuento de Borges «Las ruinas circulares» (Ficciones, 1944) o la película de Robert Wiene, El gabinete del doctor Caligari (1920), como si el hombre fuera el sueño de otro, como si una maldición pesara sobre la condición humana.
Nuevos tiempos, nuevas tecnologías, nuevas mitologías, pero la duda sigue siendo la misma, acentuada por la degradación del entorno natural y social: ¿es tal la realidad que veo, y la historia que me cuentan sobre ella? ¿Nos pertenece nuestra historia? ¿Quien se cree despierto y consciente no es el producto del sueño de otro?

Esta indagación infinita y desesperada sobre el origen desemboca en un vértigo, el de no poder abarcarlo todo, el de sentirse alienado por su propia condición. Delata una angustia que tiene que ver con una forma de neoexistencialismo muy de nuestros tiempos: una angustia sobre la condición humana que fomenta la reflexión; pero a diferencia del existencialismo sartriano, que confiaba en el libre albedrío (la concepción que Sartre tenía de la alienación social y de la libertad individual y colectiva), esta angustia no desemboca en ningún compromiso social, sino que vuelve al mito y genera nuevos imaginarios. En eso es profundamente regresiva.

La evasión de la realidad —con su correlato, la negación de todo «engagement» (implicación, compromiso social) - deja paso a una estrategia de recreación en lo virtual. La proyección en el futuro - con sus posibilidades de cambio - cede ante una vuelta al pasado de todos los pasados, al punto de partida de todas las historias: el Origen. Ya no estamos en la especulación futurista propia de la ciencia-ficción, sino en la simulación retroactiva, 
de corte posmoderno, un intento descabellado de reescribir la historia del hombre, un hombre sin humanidad, desposeído de su propia historia, ni siquiera dueño de su destino.

Este imaginario tiene como correlato el que gira en torno al fin de la humanidad, un imaginario del fin que irrumpe con fuerza en varias películas de reciente estreno.

\section{De la duda sobre la realidad al fin de la humanidad}

Si hay un director dado a manejar estos imaginarios de la duda, es seguramente M. Night Shyamalan. La duda en cuanto a la realidad vivida y vista es un tema recurrente en su obra. Es fundamental en este director la relación con el entorno espacio-temporal, las sospechas que pesan sobre esta relación y la intervención de fuerzas que escapan a la racionalidad humana o la trascienden, que hacen intervenir elementos físicos y metafísicos, que alteran el orden material y la percepción.

Shyamalan se sitúa siempre a caballo entre dos mundos: el propiamente mundano - el material y de los hombres- y otros mundos que tienen que ver con otras dimensiones, espirituales, sobrenaturales, metafísicas, que en todo caso sobrepasan la capacidad de entendimiento y control del hombre. Estos otros mundos se pueden interiorizar, dotan a los personajes de poderes especiales y hacen que se muevan dentro de un cierto espiritualismo, porque tienen la capacidad, mediante la mente, de alterar el orden del mundo.

En El sexto sentido, el director plantea un desdoblamiento de la realidad, que implica una desrealización del mundo vivido: lo que vivimos podría ser el resultado del sueño de otro, planteamiento muy borgiano; en $L a$ joven del agua recurre a fuerzas y poderes sobrenaturales, con sus personajes mitológicos; en After Earth a una fuerza interior de corte casi metafísico, disfrazada aquí de poder mental (la fantasmación: el poder secreto de volverse invisible para vencer el miedo y dominar al monstruo de turno).

Pero hay algo más en esta última película de corte posapocalíptico. Aquí, es el entorno en su conjunto el que ha desaparecido: los humanos ya no viven en la Tierra; la Tierra es un planeta no solo abandonado, sino peligroso, prohibido, que ha seguido su evolución al margen del hombre, donde los animales y las plantas han mutado. Se ha producido una especie de autonomización del planeta con respecto a la propia raza humana, se ha roto la relación de dominación del hombre sobre la naturaleza y la relación a secas con su planeta.

El título de la película de Shyamalan expresa bien este corte: es la vida después de..., después de la Tierra de la que huyó la humanidad, después del equilibrio entre el hombre y su entorno, después de la distinción entre 
géneros y especies. Los animales que aparecen en la película o son híbridos o están sobredimensionados; en cualquier caso, se ha roto no solo el equilibrio, sino la proporcionalidad: el hombre ya no está en su lugar en este contexto físico y animal que lo supera, lo humano se ha quedado pequeño, el planeta Tierra está como apartado.

Incluso, podríamos añadir, es un mundo de después del sentir: la figura del padre es dura y distante, es una máquina de mandar (es así también con su hijo), que impone rígidos protocolos de ejecución de las órdenes, lo mismo que los rangers - ese cuerpo de élite al estilo de los marines sesenteros- son máquinas ejecutoras. El pathos, el sentir no tienen lugar aquí, el hombre se ha deshumanizado.

Esta visión no es exclusiva de Shyamalan. En Avatar (2009), por ejemplo, también se da una relación de extrañamiento con el planeta Tierra y los hombres se apoyan en dobles más fuertes y precisos que ellos. Es fuera del planeta Tierra, en una especie de tierra prometida y primitiva, donde descubrirán otra naturaleza, exuberante, un híbrido entre el paraíso terrenal (el lugar del origen) y una naturaleza clonada (una suerte de universo paralelo) con especies y variedades inventadas, de carácter inédito.

Pero After Earth es más radical, los humanos se han llevado consigo al monstruo que quiere acabar con la humanidad y, como era de esperar (todo es previsible en la película), este se va a escapar durante el crash de la nave que devuelve a los rangers a casa y los obliga a hacer un aterrizaje forzoso en la Tierra. Lo que podría ser un viaje nostálgico al origen se convierte en infierno: el hombre ya no está adaptado a su medio natural o, más bien, ha acabado destruyéndolo y es el medio el que se ha convertido en amenaza para el hombre. Esta inversión del planteamiento ecológico (el hombre como amenaza para la naturaleza) sirve de premisa de la película y la envuelve en un clima de peligro constante cuando el hombre vuelve a su planeta de origen y el hijo del protagonista tendrá que hacer sus pruebas para superar el miedo al monstruo. En eso es posapocalíptica la cinta: ya no hay posibilidad de rescatar el entorno ni de vivir en él. La catástrofe se ha hecho efectiva, la Tierra se ha vuelto inhóspita, inhumana, inhabitable.

Dentro de la proliferación de imaginarios apocalípticos que invaden el cine (no solo comercial, sino también de autor), ¿qué es ese imaginario del fin que niega hasta lo más fundamental - la humanidad-y está presente hasta en el cine de autor? Y hay que tomar aquí la palabra humanidad en su doble sentido, como el conjunto de lo humano y también como categoría: el humano como ser sensible, lo que afecta in fine a la «condición humana» (concepto fundador del humanismo moderno: piénsese en la novela homónima de André Malraux). Es un cine en el que lo humano se da por acabado, 
por mucho que el final feliz de la película de Shyamalan, al más puro estilo hollywoodense, indique un retorno sentimental a los valores humanos.

Sin duda, este imaginario entronca con una duda fundamental - y fundamentada en la historia del siglo XXen cuanto a la capacidad de convivencia del género humano, mermada por la violencia histórica (guerras mundiales, Hiroshima, Shoah...) y marcada por las nuevas formas de violencia social, sin contar hoy en día el retorno de las guerras interétnicas y de los conflictos religiosos (o sea, enfrentamientos de corte tribal y comunitario). Con esto lo que se cuestiona es primordial: es el concepto mismo de historia en el sentido evolutivo moderno, la posibilidad de solventar los conflictos históricos, amén de la violencia vista aquí como consubstancial al hombre.

\section{Del neoexistencialismo al caos generalizado}

Dentro de esos imaginarios posapocalípticos, de visión negra y tratamiento espectacular, hay una excepción: Gravity (2013) de Alfonso Cuarón. Conocíamos a este director por películas tan diferentes como $Y$ tu mamá también (2001), Hijos de los hombres (2006) —entre otras- en las que, más allá del eclecticismo, hay un rasgo común, el tema de la soledad: soledad acompañada dentro del trío amoroso tan atípico de la primera; soledad de la madre a punto de parir cuando la fertilidad se ha extinguido en la Tierra, soledad de los últimos buenos hombres frente a las nuevas hordas, a unos bandos no claramente identificados en Hijos de los hombres. En esta película, los hombres han perdido las referencias, se ha difuminado la delimitación entre «buenos» $\mathrm{y}$ «malos», se han diluido las instancias sociales y disuelto las fuentes de poder. Todo ello desemboca en una soledad que podríamos calificar como social, que va más allá del individuo, que surge de la desaparición de lo social, de la necesidad de volver a fundar una comunidad con sus redes de solidaridad y ayuda. El hombre está solo frente a otros hombres de los que no sabe nada, de los que tiene todas las razones para desconfiar.

En Hijos de los hombres, esta soledad se extiende al género humano por la terrible fatalidad que ha recaído sobre los hombres: la humanidad se ha vuelto estéril, con excepción de una mujer que está embarazada y que, para colmo, es una «refugiada» en un país (el Londres imaginario de 2027) que rechaza y persigue a los extranjeros.

En Gravity -y es el mayor acierto de la cinta-, la sensación de soledad es palpable, la incomunicación física y la pérdida de las coordenadas literalmente espacio-temporal (como cuando la protagonista no puede controlar sus movimientos, se desliza hacia el infinito, rebota sobre la nave espacial o son los objetos los que chocan con ella). El sujeto, entonces, ya no domi- 
na ni el espacio ni el tiempo (lo que va a durar esa deriva en el vacío). Esta ingravidez traduce simbólicamente el estado flotante del sujeto actual, su soledad -física y metafísica-, su deriva en los «no lugares» de la posmodernidad, en un espacio sin límites: un universo «líquido» (Bauman, 2007), que no ofrece resistencia, en el que el sujeto ya no se sitúa.

Atrás ha quedado la Tierra, como en una función interrumpida, una con templación espectacular en 3D. La Tierra es el objeto perdido y, con ella, la humanidad y es precisamente esta distancia la que permite al hombre romper con lo que es o ha sido o no quiere ser.

A esta forma de angustia, experimentada en la carne, la he llamado «neoexistencialismo». Es social -el hombre ya no tiene su lugar en el entorno-, pero ese sentimiento de soledad se traduce en «síntomas» físicos, no pasa por una reflexión ontológica, como en el existencialismo histórico (El ser y la nada de Jean-Paul Sartre). Aparece en muchas películas de hoy, con su fisicidad, su manera de representar la relación con el mundo y con el otro, o incluso el estar-en-el-mundo (l'être-au-monde, Sartre) a partir de las sensaciones, de lo in-mediato, lo no mediado por la mente, lo que no pasa por el filtro del análisis y -hasta cierto punto- de la conciencia, un cine del inconsciente y de lo fantasmático de alguna manera.
¿Cómo no pensar en la magistral $E l$ tiempo del lobo (2003) de Michael Haneke - aunque su tratamiento sea mucho más alegórico-, con su conversión de la humanidad (de lo que queda de ella) en horda salvaje, la transformación de los hombres en espectros que huyen en la noche y vuelven a un estadio presocial. Si esta «estética de la desaparición» —asociada a la descomposición de lo social- ya estaba en La carretera (2009) de John Hillcoat y en Hijos de los hombres del propio Cuarón, en Gravity el director la despoja al máximo y le devuelve un aire de humanismo al planteamiento, llevando el imaginario del fin hacia una resolución humanista, una revisión de lo que ha sido uno, que le permite al sujeto redimirse. En Cuarón, la pulsión de vida, el deseo de supervivencia siempre vence al caos o al vacío.

En cambio, son más radicales los planteamientos apocalípticos de Steven Soderbergh en Contagio (2011) o de Marc Forster en Guerra mundial Z (2013), con su regresión — la vuelta de la humanidad a la horda primitiva-, su imaginario del contagio, como si fuera ineluctable este retroceso civilizacional. En Contagio, un virus de efectos devastadores diezma a la humanidad, atacando primero, y de manera totalmente aleatoria, a la gente famosa y provocando un caos generalizado que demuestra la incompetencia de las autoridades frente a su extensión fulminante. Se teme que sea un arma bio- 
lógica destinada a causar terror el fin de semana de Acción de Gracias. Al final, nos enteraremos de que ha sido producto del azar. Más virus en Guerra mundial $Z$, pero esta vez va en serio: el hombre regresa al estadio animal, entre lobo y zombi. Mediante mordeduras transmite el virus. Las masas contaminadas, cual hormigas feroces, se extienden por el plantea, llegarán a trepar por las murallas de Jerusalén en una escena que, si no fuera tópico y redundante aquí, podríamos calificar de bíblica.

Elysium (2013), de Neill Blomkamp, nos proyecta en una época en la que los hombres abandonan la Tierra, pero este abandono es clasista. A raíz de la superpoblación y de la contaminación del orbe, las élites y los más pudientes han huido del planeta y se han instalado en un nuevo hábitat: una gigantesca estación espacial en forma de anillo llamada Elysium (unos Campos Elíseos posmodernos), donde curiosamente proliferan las plantaciones de marihuana... El resto de la población - o sea, la inmensa mayoría de los humanos- sobrevive abandonado en una desolada Tierra. Privados de todo, hasta de su ciudadanía (que está reservada para los privilegiados habitantes de Elysium), los hombres viven hacinados y amenazados por el hambre y las enfermedades. El planeta Tierra ya no es habitable. El caos se ha generalizado. Pero también en el mejor de los mundos posibles —en la lujosa e impoluta Elysium-, se desatan las pasiones y se manifiestan las ambiciones, hasta que, de las ruinas de Los Ángeles y del lumpen en que se ha convertido su población, surge un héroe redentor, un ángel vengador.

La figura de la autodestrucción encuentra su máxima expresión en Los juegos del hambre (2012), basada en la novela best seller del mismo nombre de Suzanne Collins. En una imaginaria nación llamada Panem [sic], levantada sobre las ruinas de lo que fueron los Estados Unidos de Norteamérica, se celebran cada año los juegos del hambre para recordar a los doce distritos, el castigo por su rebelión setenta años atrás. Mediante sorteo se elige a un chico y a una chica de cada distrito, de edades comprendidas entre los doce y los dieciocho años para someterlos a una competencia en la que tendrán que luchar hasta que solo quede uno. El vencedor será premiado con suministro de víveres, todo ello debidamente espectacularizado con retransmisiones y pantallas gigantes, con el asesoramiento de estilistas que preparan a los concursantes para complacer a los patrocinadores. Entre los juegos romanos de gladiadores y el reality show moderno, este concurso de supervivencia para público quinceañero se asienta sobre la eliminación física de los demás concursantes, convertida en juego, como en Battle Royale (2000), la película de Kinji Fukasaku. En un retroceso a la primitiva ley de la 
selva cruzada con la moderna ley del espectáculo, se mezclan aquí sadismo y espectáculo, castigo y juego, presión social y deleite del público mediante un autosacrificio: para cumplir con las reglas y, en el caso de ganar, sacar provecho de ello, recibiendo comida extra a cambio. El circo romano se ha integrado a la gestión del Estado y al control de la sociedad.

\section{Conclusión: ¿el fin de lo humano?}

En estas producciones, la visión es radical, en el sentido en que niega algo consubstancial a la civilización, la capacidad del hombre de superar su propia historia. Parte de un presupuesto -aunque ficticio, del orden de lo imaginario- de que ya no hay humanidad, bien sea porque ha desaparecido la Tierra como conquista del hombre, la naturaleza y el reino animal han vuelto a tomar posesión de ella ( $A f-$ ter Earth); o porque el planeta ha sido totalmente arrasado (La carretera), aniquilado (como en tantas películas de ciencia-ficción), o porque está a punto de desaparecer por el choque con otro planeta (Melancolía). Que se trate de visiones pre o pos apocalípticas, la creencia implícita es la misma: dan por sentada la degradación de la condición humana, el hombre ya no vale por sí mismo, no es capaz de mantener su planeta ni de defender al género humano. Por otra parte, lo humano ya no funciona como valor, ni valor en sí —del orden de lo ético-, ni valor ecológico de respeto y mantenimiento del entorno.

Tras todo ello está un imaginario emergente en muchas películas actuales: el fin de la humanidad, ya sea como territorio, ya sea en forma de falta de creencia en el valor humano. Con esto nos alejamos de valores que han sustentado el pensamiento moderno y que implicaban visiones del mundo basadas tanto en las ciencias físicas como sociales: las teorías de la evolución (el darwinismo), con su correlato de la fe en el hombre (en su avance y su capacidad de adaptación), la creencia en la historia (el progreso), la proyección en las ideologías (la voluntad de cambio), para desembocar en una visión ahistórica e incluso, a veces, antihistórica. La separación con el planeta va pareja con un corte epistemológico, dentro de una visión que separa al hombre de su entorno, lo aísla y le quita todo poder de incidencia sobre el curso de su propia historia.

¿Es esta una nueva forma de conformismo, de negación de la historia (como en las teorías revisionistas)? ¿En qué medida no vuelve a mentalidades primitivas que conllevan la creencia en otros mundos (sobrenaturales, secretos, invisibles, e incluso interiores, sobrehumanos)? Shyamalan está de pleno en ello, entre un ecologismo de pacotilla y un new age light disfrazado de espiritualidad. Pero otros se lo toman más en serio, hasta, a veces, de manera trágica o melancólica, como Béla Tarr o Lars von Trier. 


\section{Referencias}

Baudrillard, J. (1978). La précession des simulacres. París: Minuit. (Traducción española: Cultura y simulacro. Barcelona: Kairós, 1978).

Bauman, Z. (2005). Modernidad y ambivalencia. Barcelona: Anthropos.

Bauman, Z. (2007). Miedo líquido: la sociedad contemporánea y sus temores. Barcelona: Paidós.
Imbert, G. (2010a). Cine e imaginarios sociales. El cine posmoderno como experiencia de los límites (1990-2010). Madrid: Cátedra.

Imbert, G. (2010b). La sociedad informe. Posmodernidad, ambivalencia y juego con los límites. Barcelona: Icaria. 